\title{
Knowledge Regarding Gastritis among Late Adolescence in Central Nepal
}

\author{
Sashi Silwal ${ }^{1 *}$, Astha Acharya ${ }^{1}$, Bimala Baral $^{2}$, Anirudra Devkota $^{2}$, Aadesh Subedee $^{3}$, Uttam \\ Paudel $^{1}$ \\ ${ }^{I}$ Nepal Health Research Council \\ ${ }^{2}$ Central Department of Home Sciences, Tribhuvan University \\ ${ }^{3}$ Kathmandu University \\ ${ }^{4}$ Chitwan Medical College \\ *Corresponding Author
}

\begin{abstract}
Gastritis is an inflammation or irritation of the lining of the stomach, can be a brief and sudden illness (acute gastritis), a long-lasting condition (chronic gastritis). Gastritis is the top most common cause of morbidity. This study is designed to find out knowledge regarding gastritis among late adolescence. A descriptive research design was used for the study. A semi-structured self-administered questionnaire was used to collect the data. Data were analysed and the descriptive and inferential test was applied by using SPSS. The study finding revealed eighty percent of the participants knew the definition of gastritis, $66 \%$ on risk factors, $50 \%$ respondents on causes, $23.7 \%$ on sign and symptom,56.66\% on management and 48.5\% respondents on complications, and $66.55 \%$ on prevention of gastritis. The level of knowledge is average in causes, signs and symptoms, management and complications. More specifically, 68\% of respondents had average knowledge on gastritis and 4\% had excellent knowledge. The level of knowledge of respondents is statistically significant with sex $(p=0.021)$ and socio-economic status ( $p=0.008)$. The finding of the study revealed that knowledge on gastritis is average among the respondents. So the health education is needed for students to increase their knowledge.
\end{abstract}

Keywords: gastritis, central Nepal, late adolescence, knowledge level

\section{INTRODUCTION}

Gastritis is an inflammation or irritation of the lining of the stomach, can be a brief and sudden illness (acute gastritis), a long-lasting condition (chronic gastritis). Occasionally, a rare form of gastritis can be serious or even life-threatening due to ongoing symptoms or internal bleeding (Smeltzer et al., 2008). This disease is also described as peptic ulcer or acid peptic disease (Sakya, 2014).H. pylori are the causative agent in more than $90 \%$ of cases of chronic gastritis/peptic ulcer disease (Adisa et al., 2011). An estimated 50\% of the world population is infected with H. pylori, an infection that leads to the greater majority of Gastritis cases; therefore, chronic gastritis is extremely frequent. Gastritis is highly prevalent in Asia and in developing countries and etiological factor for gastritis was autoimmune disorders, life style changes, stress, intake of coffee and acidic beverages, spicy and carbonated foods, backflow of bile into the stomach (bile reflux), pernicious anaemia, long term use of NSAIDs, smoking and alcoholism (Lewis et al., 2007). 
Prevalence in developing countries is generally over $80 \%$ as compared to $20-50 \%$ in industrialized countries. The overall prevalence of $\mathrm{H}$. pylori infection is strongly correlated with socioeconomic conditions and prevalence tends to increase with age (Suerbaum \& Michetti, 2002). The incidence of gastritis by $\mathrm{H}$ pylori in European adults is $70 \%$, Asian countries such as $90 \%$ in Bangladesh adults and $88 \%$ among Indian adults. There may be similarly wide variations in the prevalence between more affluent urban populations and rural populations (Hunt et al., 2010). In India, nearly $10 \%$ of people who come to a hospital emergency department with abdominal pain have gastritis (Rugge et al., 2011).In Nepal, the most common endoscopic findings are gastritis (47.6\%) followed by normal findings of $17.87 \%$. Among the cases, three hundred nineteen are dyspeptic patients (Male 161 and female 152) with a mean age of 20.12 years (Shrestha et al., 2012).

Gastritis is a National illness for Nepalese all over the country as their timing of taking food and their daily life chores are supporting to suffer from gastric for each people (Sakya,2014). However, chronic gastritis is still one of the most common serious pandemic infections with such severe killing sequelae as peptic ulcer or gastric cancer (Sipponen \& Maaroos, 2015)Various studies have revealed that the occurrence of gastritis is increasing with age and knowledge on it is inadequate. It has recognized one of the most prevailing diseases which have been resulting elevating rate of morbidity among peoples but limited studies are available on gastritis in Nepal (Shakya et al., 2017). Therefore, this study aims to explore the knowledge on gastritis among youngsters in Central Nepal which might provide baseline information for other similar settings.

\section{METHODS}

\section{Research Design}

A descriptive cross-section research design was employed to identify the knowledge regarding gastritis among bachelor students. The study was conducted at Presidency College of Management Sciences Bharatpur -10, Chitwan. All bachelor-level students from the commerce stream were the population for the study. The Census method was used and all the 50 students were taken as sample size. Data were entered into Excel and analyzed using SPSS software.

\section{Data Collection}

A semi-structured questionnaire was administered for data collection procedure to identify the knowledge regarding gastritis among bachelor students and a questionnaire was prepared by researchers based on reviewed literature. The research instrument was divided into two parts:

Part I: Question related to demographic information

Part II: Question related to knowledge regarding gastritis

To observe the Level of Knowledge among youngsters, a separate leveling scale was prepared which explained the score achieved by respondents that were measured by calculating 
the total score and then classified into 4 categories. Level of knowledge: Below average $<40 \%$, Average knowledge 41-60\%, Good knowledge 61-80\%, and excellent knowledge 81-100\%.

\section{Validity and Reliability}

Validity of the research instrument was ascertained with the help with literature review and by consulting the research advisor and subject expert. The reliability of the research instrument will be maintained through pretesting in $10 \%$ of the sample size ( 5 respondents) in a similar setting. The necessary modification was done after pretesting.

\section{Data Collection Procedure}

Ethical approval was taken from Chitwan medical college. Permission was taken from the Presidency College of Management Sciences. Written consent was taken from all respondents. Privacy was maintained by taking the information from respondents separately. The researcher collected the data herself within 2 weeks from 2071/08/14 to 2071/08/21 by questionnaire schedule. Confidentiality of the subjects was maintained by assuring them that the information given by them would not be disclosed and would be used only for study.

\section{Data Analysis}

The collected data was checked, reviewed and organized for accuracy and completeness. After that data was coded and entered in SPSS. The collected data was analyzed using descriptive (Frequency percentage) and inferential (chi-square test) statistical methods.

\section{RESULTS}

\section{Respondents'Socio-demographic Characteristics}

Of the total respondents, less than half of the participants (38\%) were19 years of age, very few participants $(10 \%)$ were 22 years of age. Mean \pm SD age was $19.70 \pm 1.19$ years. Similarly, the minimum age was 18 and the maximum was 22 years. Concerning gender, less than half $(46 \%)$ of the respondents were male \& more than half respondents $(54 \%)$ were female. Concerning part-time jobs, $40(80 \%)$ respondents have no part-time job and the remaining respondents $10(20 \%)$ had part-time jobs (Table 1). Among the respondents who had part-time jobs, $9(18 \%)$ were employed in private service and $1(2 \%)$ was in government service. As regards socioeconomic status, half of the respondents answered their socio-economic status is sufficient for more than 12 months and $5(10 \%)$ respondents answered their socio-economic status is sufficient for 6 months for their livelihood. Concerning the previous history of gastritis, more than half of respondents had no previous history and $18(36 \%)$ had mentioned the history of gastritis. However, the majority of respondents $(70 \%)$ had mentioned the history of gastritis in their family. About $30 \%$ of respondents had no family history and among them who had a previous history of gastritis, $17(36 \%)$ were mothers (highest) and 3(6\%) were aunty and grandmother. 
Table 1: Demographic and Social Aspects of the Participants

\begin{tabular}{|c|c|c|}
\hline Variables & Frequency & Percentage \\
\hline \multicolumn{3}{|l|}{$\overline{\text { Age (in years) }}$} \\
\hline 18 & 7 & 14 \\
\hline 19 & 19 & 38 \\
\hline 20 & 11 & 22 \\
\hline 21 & 8 & 16 \\
\hline 22 & 5 & 10 \\
\hline \multicolumn{3}{|l|}{$($ Mean \pm SD $)$ age $=(19.70 \pm 1.19)$ years } \\
\hline \multicolumn{3}{|l|}{ Sex } \\
\hline Male & 23 & 46 \\
\hline Female & 27 & 47 \\
\hline \multicolumn{3}{|l|}{ Part-time job } \\
\hline Yes & 10 & 20 \\
\hline No & 40 & 80 \\
\hline \multicolumn{3}{|l|}{ If yes types of occupation $(n=10)$} \\
\hline Private service & 9 & 18 \\
\hline Government service & 1 & 2 \\
\hline \multicolumn{3}{|l|}{ Socioeconomic status of their family } \\
\hline Sufficient for livelihood less than six months & 9 & 18 \\
\hline Sufficient for six month & 5 & 10 \\
\hline Sufficient for 6-12 month & 11 & 22 \\
\hline Sufficient for more than 12 months & 25 & 50 \\
\hline \multicolumn{3}{|l|}{ Previous History of Gastritis } \\
\hline Yes & 18 & 36.0 \\
\hline No & 32 & 64.0 \\
\hline \multicolumn{3}{|l|}{ Family History of Gastritis } \\
\hline Yes & 35 & 70,0 \\
\hline No & 15 & 30.0 \\
\hline \multicolumn{3}{|l|}{ If yes relation with respondents } \\
\hline Aunty & 1 & 2.0 \\
\hline Mother & 17 & 36.0 \\
\hline Father & 12 & 24.0 \\
\hline Grandfather & 1 & 2 \\
\hline Grandmother & 2 & 4.0 \\
\hline Brother & 4 & 8.0 \\
\hline Sister & 2 & 4.0 \\
\hline
\end{tabular}

Out of the total, more than half of the respondents $(60 \%)$ got the information from newspapers and magazines while $42 \%$ of respondents got the information from health personal (Table 2). 
Table 2: Source of Knowledge for Gastritis

\begin{tabular}{lcc}
\hline Source of Information & Frequency & Percentage \\
\hline Newspaper and magazine & 30 & 60.0 \\
Radio & 25 & 50.0 \\
Television & 30 & 60.0 \\
Health worker & 21 & 42.0 \\
College/ teacher & 28 & 56.0 \\
Family friend ,neighbor & 23 & 46.0 \\
\hline
\end{tabular}

Of the total participants, a majority $(80 \%)$ of them answered inflammation of stomach mucosal lining as the definition of gastritis and very few (2\%) respondents answered inflammation of the liver (Table 3).

\section{Table 3: Knowledge regarding Definition of Gastritis}

\begin{tabular}{lcc}
\hline Definition & Frequency & Percentage \\
\hline Inflammation of stomach mucosal lining* & 40 & 80 \\
Inflammation of the large intestine & 4 & 8 \\
Inflammation of the small intestine & 5 & 10 \\
Inflammation of liver & 1 & 2 \\
\hline
\end{tabular}

*Correct response

\section{Knowledge on Risk Factors and Personal Habits for Developing Gastritis}

Of the total participants, almost all (98\%) respondents answered contaminated food as a risk factor for developing gastritis and few (4\%) respondents answered eating green vegetables (Figure 1). Regarding personal habits, $34(68 \%)$ respondents answered the use of coffee as the personal habits causing gastritis and $5(10 \%)$ respondents answered drinking plenty of water (Figure 2).

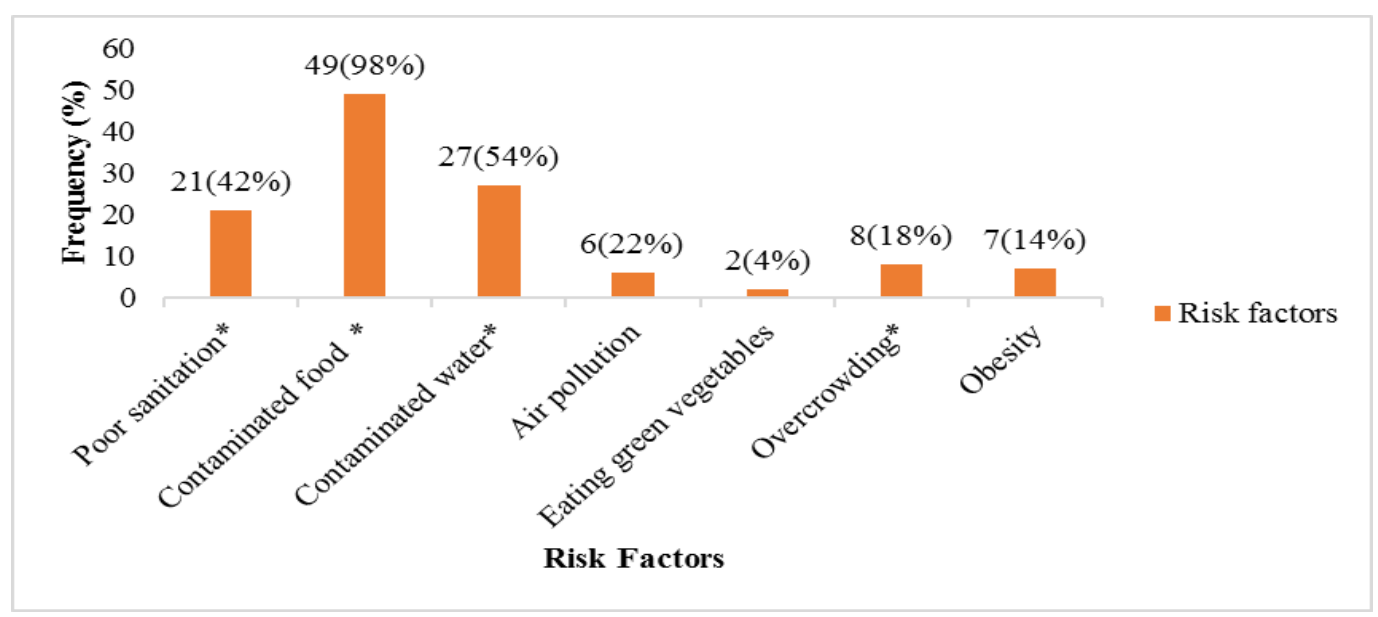

Figure 1: Knowledge of Risk Factors 
*Correct response, $* *$ Multiple responses

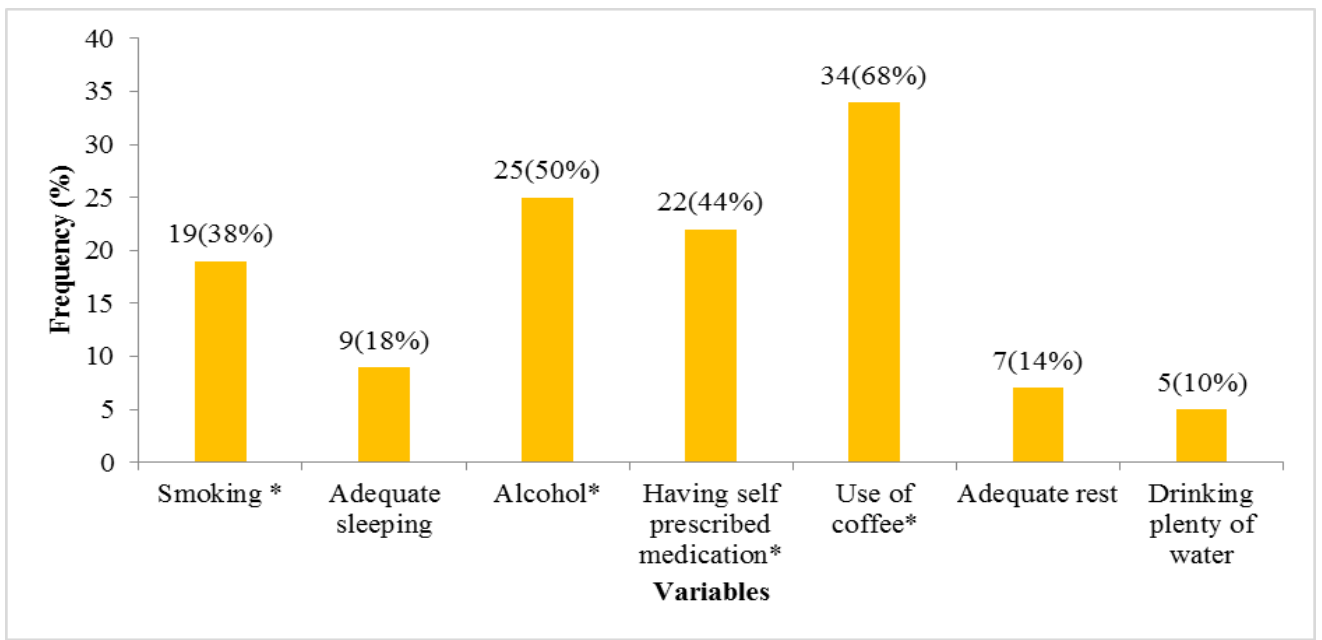

\section{Figure 2: Knowledge of Personal Habits}

*Correct response, $* *$ Multiple responses

\section{Knowledge on Causative Organism and Stress Causing Gastritis}

Out of total respondents, less than half (42\%) respondents answered bacteria as the causes of gastritis and 10\%) respondents answered helminthes (Figure 3). About stress causes gastritis, $58 \%$ of respondents stand for favor and $42 \%$ of respondents seem not in favor.

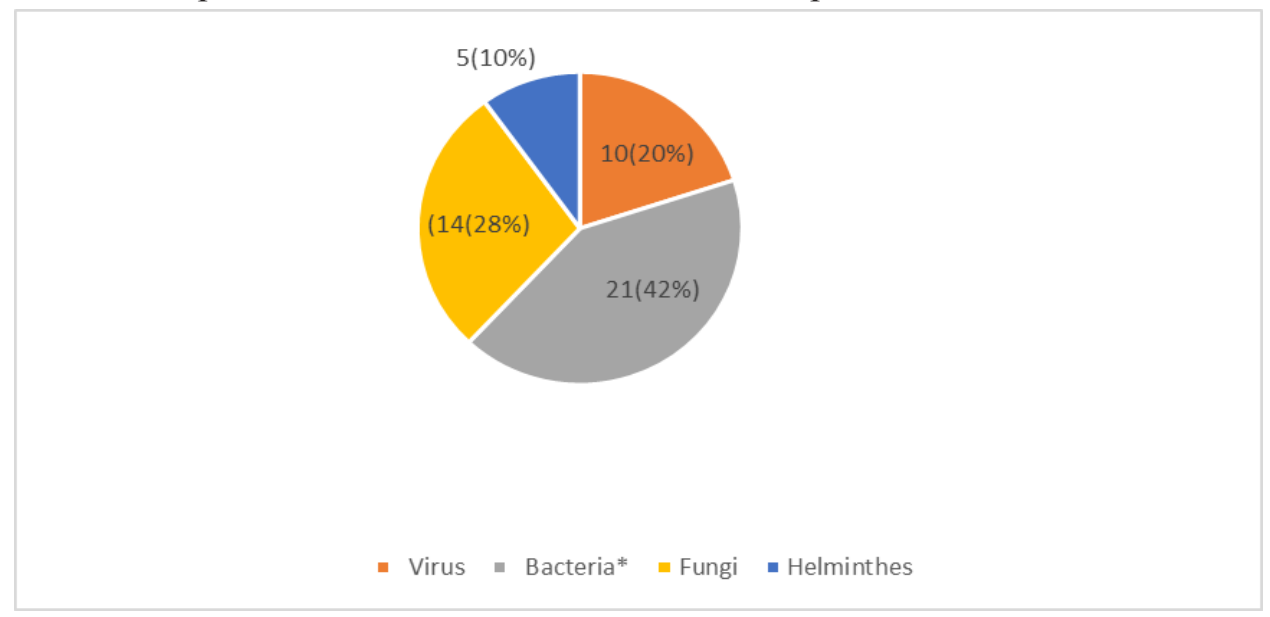

\section{Figure 3: Knowledge on Causative Organism}

*Correct response ** Multiple responses

\section{Knowledge on Foods and Disease Condition for Developing Gastritis}

Out of all respondents, it is seen that majority of the respondents $(84 \%)$ answered spicy food trigger for developing gastritis whereas few respondents (4\%) answered green vegetables as triggering food for developing gastritis (Table 4). Similarly, more than half of the respondents 
$(60 \%)$ answered that gastritis can be caused by Chorns disease and $10 \%$ of youngsters believed in heart disease.

Table 4: Knowledge on Foods and Disease Condition for Developing Gastritis

\begin{tabular}{lcc}
\hline Variables & Frequency & Percentage \\
\hline Triggering food ** & 5 & 10.0 \\
Fruits & 42 & 84.0 \\
Spicy food * & 40 & 80.0 \\
Junk food* & 32 & 64.0 \\
Fat diet* & 8 & 16.0 \\
Soft drink* & 3 & 6.0 \\
Calcium and vitamin intake & 2 & 4.0 \\
Green vegetables & & \\
Disease condition** & 24 & 48.0 \\
Diabetic mellitus* & 9 & 18.0 \\
Chronic obstructive pulmonary & & \\
disease* & 5 & 10.0 \\
Heart disease* & 30 & 60.0 \\
Chorns disease* & 12 & 24.0 \\
Urinary tract infection & 11 & 22.0 \\
Ear disease & 10 & 20.0 \\
Chlolelithesis & &
\end{tabular}

*Correct response ** Multiple responses

\section{Knowledge regarding Signs and Symptoms and Complications of Gastritis}

Out of the total respondents, the majority of the youngsters (70\%) reacted for abdominal pain and more than half of them (58\%) responded vomiting and only $2 \%$ believed fever as a symptom of gastritis (Table 5). Concerning the complication of gastritis, $64 \%$ of the youngsters answered stomach cancer and $6 \%$ of the participants answered pneumonia.

Table 5: Description of Sign and Symptoms and Complications of Gastritis

\begin{tabular}{lcc}
\hline Variables & Frequency & Percentage \\
\hline Sign and symptoms & & \\
Hiccups * & 15 & 30.0 \\
Vomiting* & 29 & 58.0 \\
Indigestion* & 42 & 84.0 \\
Abdominal pain* & 35 & 70.0 \\
Headache & 8 & 16.0 \\
Back pain & 6 & 12.0 \\
Fever & 1 & 2.0 \\
\hline
\end{tabular}




\section{Complication}

Stomach cancer

32

4

3

pneumonia

Joint pain

10

13

36

Chronic gastritis

Gastrointestinal bleeding

*Correct response ** Multiple responses
64.0

8.0

6.0

20.0

26.0

72.0

32.0

\section{Knowledge regarding Management of Gastritis}

Out of the total respondents, almost $90 \%$ of them replied that gastritis is curable and $15 \%$ responded gastritis is not curable, majority of the respondents $(68 \%)$ answered eating a balanced diet as self-management of gastritis at home and $14 \%$ youngsters answered eating too much (Table 6$)$. The majority of the respondents $(70 \%)$ reacted gastritis can be treated by medicine and more than a quarter (30\%) respondents mentioned gastritis cannot be treated by medicine. Out of 35 respondents' majority of the respondents $(74.28 \%)$ believed that gastritis can be managed by medicine and there is a need for the complete course of medicine to treat gastritis (Figure 4).

Table 6: Management of Gastritis

\begin{tabular}{lcc}
\hline Variables & Frequency & Percentage \\
\hline Managed by Medicine & 35 & 70 \\
$\quad$ Yes* & 15 & 30 \\
No & & \\
If yes Complete course of medicine $\mathbf{n}=\mathbf{3 5}$ & 26 & 74.28 \\
Yes* & 9 & 25.71 \\
No &
\end{tabular}

*Correct response ** Multiple responses

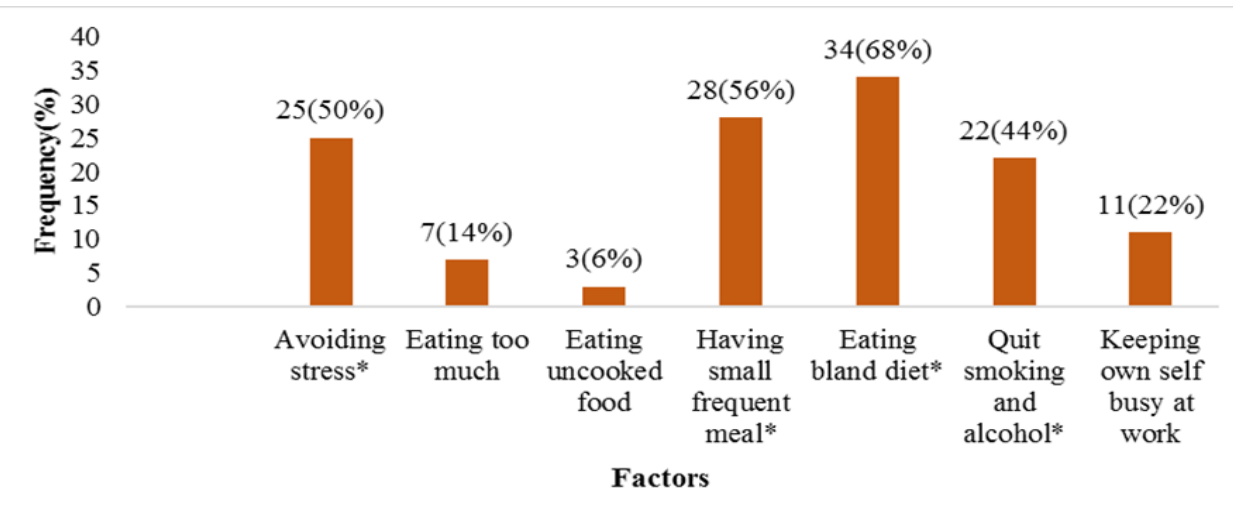

Figure 4: Self-management of Gastritis at Home 


\section{Knowledge regarding Prevention of Gastritis}

It is observed that almost $98 \%$ of youngsters believed that gastritis can be prevented by avoiding spicy foods and $12 \%$ of respondents purported having bedtime snacks for prevention of gastritis.

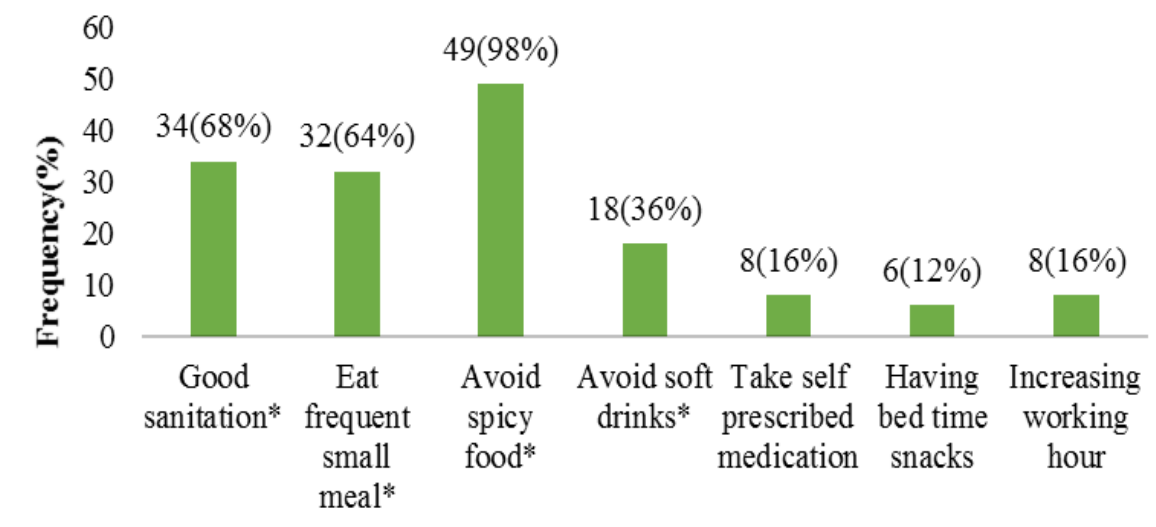

Variables

\section{Figure 5: Knowledge regarding Prevention of Gastritis}

$*$ Correct response $* *$ Multiple responses

\section{Respondents' Level of Knowledge regarding Gastritis}

Out of all respondents, it is seen that the majority (68\%) respondents had average knowledge and a few respondents 2 (4\%) had excellent knowledge (Figure 6). The level of knowledge was merged (below average and average $=$ average and good and excellent $=$ good) for further statistical analysis to find out the association.

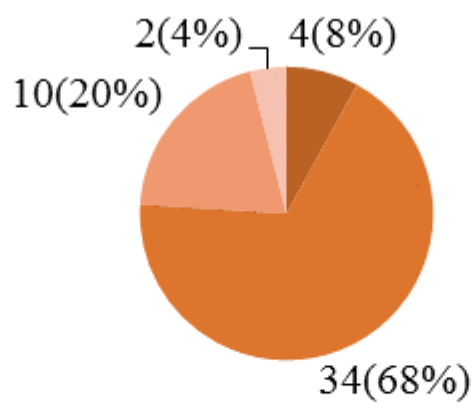

Below average

Good knowledge
Average knowledge Excellent knowledge 
Association between Respondent's Level of Knowledge and Selected Demographic Variables

Out of all respondents, it is shown that the level of knowledge regarding gastritis is significant with $\operatorname{sex}(\mathrm{p}=0.021)$ and socio-economic status $(\mathrm{p}=0.008) \chi 2$ is computed for statistical value (Table 7). Hence, it is seen that the level of knowledge is not significant with a part-time job $(p=0.619)$, history of gastritis $(p=0.639)$ and family history of gastritis $(p=0.773)$.

Table 7: Results of Associations between Knowledge of Gastric and Demographic Variables

\begin{tabular}{lccc}
\hline \multirow{2}{*}{ Variables } & \multicolumn{2}{c}{ Level of knowledge } & \\
\cline { 2 - 4 } Sex & \multicolumn{1}{c}{ Poor } & Good & P-value \\
Male & $14(60.9 \%)$ & $9(39.1 \%)$ & $0.021^{*}$ \\
Female & $24(88.9 \%)$ & $3(11.1)$ & \\
Socio economic status & & & $.008^{*}$ \\
Low & $23(92.0 \%)$ & $2(8.0 \%)$ & 0.619 \\
High & $15(60.0 \%)$ & $10(40.0 \%)$ & \\
Part-time job & & & \\
Yes & $7(70 \%)$ & $3(30.0 \%)$ & 0.639 \\
No & $31(77.5 \%)$ & $9(22.5 \%)$ & \\
History of gastritis & & & \\
Yes & $13(72.2 \%)$ & $5(27.8 \%)$ & 0.773 \\
No & $25(78.1 \%)$ & $7(21.9 \%)$ & \\
Family history of gastritis & & & \\
Yes & $27(77.1 \%)$ & $8(22.9 \%)$ & \\
No & $11(73.3 \%)$ & $4(26.74 \%)$ & \\
\hline
\end{tabular}

*Correct response

\section{DISCUSSION}

The study was conducted to find out the knowledge regarding Gastritis among late adolescence in Central Nepal. It was revealed that adolescences agreed contaminated food as the major risk factor for gastritis while a few of them also reported green vegetables as the risk factor for gastritis. The study also showed that majority of adolescences believed - gastritis is curable. The majority of respondents said eating a balanced diet is the best way to manage gastritis at home, while according to the majority of respondents ( $70 \%)$ gastritis can be cured by medicine.

This study also showed that the male sex is significant to influence the level of knowledge. This result is opposite to a study conducted by Fating and Sharma (2019) which showed a significant association between the knowledge scores with demographic variables except for gender. However, for demographic variables, the finding of this study is consistent with a study conducted by Padmavathi (2013) which showed a significant association between the knowledge scores, factors influencing scores with selected demographic variables. 
Our study revealed that $80 \%$ of late adolescence knew the definition of gastritis, $66 \%$ on risk factors, $50 \%$ on causes, $23.7 \%$ on signs and symptoms, $56.66 \%$ on management, $48.5 \%$ on complication, $66.55 \%$ on prevention whereas inconsistent findings by Padmavathi et al., (2013) revealed $54.80 \%$ adolescence had knowledge on definition regarding gastritis, $48.50 \%$ risk factor, $36 \%$ causes of gastritis, $47 \%$ sign and symptoms, $50.75 \%$ on management, $41 \%$ on complication, $40.50 \%$ had knowledge on prevention of gastritis.

In this study, $42 \%$ of late adolescence knew contaminated water as a risk factor for developing gastritis and $18 \%$ of them answered overcrowding. The finding of the study is supported by Charles et al. (2000) which revealed that $35.8 \%$ of participants knew overcrowding and $38.1 \%$ of participants on contaminated water. Similarly, the finding of the study regarding knowledge on smoking and alcohol as a personal habit causing gastritis are also inconsistent with the finding of the study Charles et al. (2000). However, our study findings are thoroughly consistent with Novelli, (1997) regarding the knowledge about causes of peptic ulcer caused by bacterial infection and spicy foods as a risk factor for developing gastritis. The finding of this study showed that stress is a cause of gastritis which is consistent with the results of a study by Novellli (1997) but inconsistent with Charles et al. (2000) and lee et al. (2001).

This study revealed that late adolescence has an average level of knowledge on gastritis and its consequences. Similarly, the finding of the study showed that male sex and demographic characteristics are major influencers on gastritis prevalence among late adolescence. It is critical to think that the health sector program needs to focus on a community-level knowledge enhancement programme regarding gastritis, focusing on the male sex and considering the sociodemographic characteristics of the community in central Nepal.

\section{CONCLUSION}

This study has explored the overall level of knowledge of gastritis among late adolescence. The level of knowledge regarding gastritis is good in a domain like definition, risk factors and prevention, average in causes, signs and symptoms, management, complication. The level of knowledge among late adolescence is at an average level and is significantly associated with gender and socioeconomic status. So the health sector program should focus on gastritis related health-education interventions to increase the level of knowledge on controlling the prevalence of gastritis problems among late adolescence.

\section{Limitations of the Study}

The study population is confined to bachelor-level students of Central Nepal. The study is limited to central Nepal, therefore the finding of the study cannot be generalized to the whole country. 


\section{REFERENCES}

Adisa , J.O., Musa, A.B., Yima U.I and Egbujo, E.C. (2011). Helicobacter Pylori associated Gastritis in North-Eastern Nigeria: A histopathologic study. E-International Scientific Research Journal3(1):2094-1749,

Retrieved from

www.researchgate.net/...Gastritis...Nigeria.../0912f50990c84ce37100000.pdf

Annual report Department of the Health service 2075/2076 Retrived from

https://dohs.gov.np/wp-content/uploads/2020/11/DoHS-Annual-Report-FY-075-76-. pdf

Charles, C., Sue, M., Lord, C., Morris. E., Edwards, S., Peura. P \& Hope, M. (2000).

Knowledge/awareness of gastritis/peptic ulcer diseases in guyana.

GastroenterologyJ 118(4):2-1221Retrieved from

http://www.gastrojournal.org/article/S0016-5085(00)80719-

2/abstract?referrer=http\%3A\%2F\%2Fwww.gastrojournal.org\%2Farticle\%2FS00165085\%2800\%2980719-2\%2Fabstract

Fating SS, Sharma R. (2019). Assess the knowledge regarding risk factors of Gastritis among second year engineering students. Adv Practice Nurs 4:162

https://www.hilarispublisher.com/open-access/assess-the-knowledge-regarding-riskfactors-of-gastritis-among-second-year-engineering-students.pdf

Hemavathy V, Girijabhaskaran, Valentina Devi VT. (2016). A study to assess the knowledge on gastritis among 2nd year B. Sc. nursing students in Sree Balaji College of Nursing, Chennai. Int J Appl Res 2: 254-56. Microsoft Word - 2-3-141.1.doc (allresearchjournal.com) ISSN Print: 2394-7500 ISSN Online: 2394-5869 Impact Factor: 5.2 IJAR 2016; 2(4): 254-256

HLA-DQA1 \& HLA-DQB1 Genotyping in gastritis patients with positive RUT - Scientific figure on Research Gate. Retrieved from: https://www.researchgate.net/figure/Frequencies-ofgastritis-patients-chronic-acute-according-to-RUT-results_tb12_255409316

Hungampola1, O., Samarakoon, S., Perera, D., Perera, H., Silva, D \& amp; Buddhika, H. (2013). Factors influencing gastritis: a preliminary study for assessment of knowledge, attitudes and practices among patients with gastritis. Retrieved from http://digital.lib.ou.ac.lk/docs/bitstream/701300122/662/1/NSC\%2037.pdf

Hunt, R.H., Xiao, S.D., Megraud, F., Barua, R.L., Bazzoli, F., Merwe, S., Coelho, V., Fock, M., Fedail, S., Cohen, H., Malfertheiner, P., Vakil, N., Hamid, S., Goh, K.L, Wong, B.C.Y, Krabshuis, J. \& Mair, A.L. (2010). Helicobactor Pylori in developing countries.

Retrieved from

http://www.worldgastroenterology.org/assets/downloads/en/pdf/guidelines/11_helicobact er_pylori_developing_countries_en.pdf 
Lee, M. G., Soyibo, K., Garro, I.O., Phillips. N \& Dale, B. (2001). Peptic ulcer disease and Jamaican patients' awareness of their disorder west India medical j.44(2):58-9. Retrieved fromhttp://www.ncbi.nlm.nih.gov/pubmed/7667971

Lewis, S., Helkeimper, M., Driksen, S., O'Brien, P., \& Bucher, L. (2007). Text book of medical surgical nursing (7th ed.). Philadelphia: New Delhi: Mosby Publications) Retrived from: https://www.elsevier.com/books/medical-surgical-nursing/lewis/978-0-323-32852-4

Novelli, P.(1997 ). Knowledge about causes of peptic Ulcer disease. MMWR J 46(42);985-987 Retrieved fromhttp://wonder.cdc.gov/wonder/prevguid/m0049679/m0049679.asp\#head00200

Padmavathi, G.V., Nagaraju, B., Shampalatha, S.P., Nirmala, M., Begum, F., Susan, T.T., Pavani, G.V. (2013). Knowledge and factors influencing on Gastritis among distant mode learners of various universities at selected study centers around Bangalore City with a view of providing a pamphlet. An International Publisher for Academic and Scientific Resources. 1(2):101-110Retrieved from http://saspublisher.com/wpcontent/uploads/2013/04/SJAMS12101-11 Padmavathi GV1

Rajashekhar, V., Bhasin, D.K., Ray, P., Vaiphei, K., Sharma, B.C \& Singh, K. (2008). Helicobacter pylori infection in chronic smokers with non ulcerdyspepsiaTrop Gastroenterol.21(2):71-2. Retrieved from www.ncbi.nlm.nih.gov/pubmed/10881628 Rugge, M., Kim, J.G., Mahachai, V., Miehlke, S., Pennelli, G., Russo, V.M., Perng, C.L., Chang, F.Y., Tandon, R.K., Singal, D. K., Sung, J.J., Valenzuela, J.E., Realdi, G., Dore, M.P. \& Graham, D.Y. ( 2008). OLGA gastritis staging in young adults and country-specific gastric cancer risk Int J SurgPathol.31(10):1104-11 Retrieved from http://www.ncbi.nlm.nih.gov/pubmed/184176716(2):150-4. doi:10.1177/1066896907307238

Shakya, R. (2014). Gastritis: a national epidemic. E kantipur.com Retrieved from http://www.ekantipur.com/2014/08/14/health-and-style/gastritis-a-nationalepidemic/393570.html

Shrestha, S., Paudel, P., Pradhan, G.B., Shrestha, L. \& Bhattachan, C.L. (2012). Prevalence study of H. pylori infection in dyspeptic patients coming to Nepal Medical College Teaching Hospital, Jorpati, Kathmandu. Nepal Med Coll J. 14(3):229-33. Retrieved from http://www.ncbi.nlm.nih.gov/pubmed/24047023

Sipponen P, Maaroos HI. Chronic gastritis. Scand J Gastroenterol. 2015 Jun; 50(6):657-67. doi: 10.3109/00365521.2015.1019918. Epub 2015 Apr 22. PMID: 25901896; PMCID: PMC4673514.

Smeltzer, S., Bare,B., Hinkie,J., \& Cheever, K. (2008). Text book of medical surgical nursing. $7^{\text {th }}$ (ed.) New Delhi: Mosbey publication

Suerbaum, S., \& Michetti, P. H. (2002). Helicobacter Pylori associated gastritis in North-Eastern Nigeria: A histopathologic study. N Engl J Med.347(15):1175-86 Retrieved form http://www.researchgate.net/publication/232815407 